\title{
Dementia and well-being: A conceptual framework based on Tom Kitwood's model of needs
}

\section{Elke G Kaufmann}

Lutheran Diakoniewerk Neuendettelsau, Germany

\section{Sabine A Engel}

Institute of Psychogerontology, Friedrich-Alexander University of Erlangen-Nuremberg, Germany

\begin{abstract}
The topic of well-being is becoming increasingly significant as a key outcome measure in dementia care. Previous work on personhood of individuals with dementia suggests that their subjective well-being can be described in terms of comfort, inclusion, identity, occupation and attachment. The study aimed to examine Tom Kitwood's model of psychological needs and well-being in dementia based on the self-report of individuals with moderate or severe dementia and to differentiate and elaborate this model in the light of the empirical qualitative data. Nineteen inhabitants of a special long-term care unit were interviewed using a semi-structured interview. Data were analysed using content analysis. Thirty components within Kitwood's model have been identified. A conceptual framework of subjective well-being in dementia was developed based on a theoretical background. The study was able to find indications that Kitwood's model has empirical relevance. Nevertheless, it requires to be extended by the domain agency. Furthermore, the study suggests that individuals with dementia are important informants of their subjective well-being.
\end{abstract}

\section{Keywords}

subjective well-being, self-report, need, person-centred care, dementia

\section{Introduction}

Researchers are currently debating the domains of well-being and the best application of methodologies to raise its profile (Ferring \& Boll, 2011; George, 2010; Langlois \& Anderson, 2002; Mak, 2011; Trigg, Watts, Jones, \& Todd, 2011). Well-being is increasingly important

Corresponding author:

Sabine A Engel, Catholic University of Applied Sciences of North Rhine-Westphalia, Leostrasse 19 D-33098 Paderborn, Germany.

Email: s.engel@katho-nrw.de 
in providing and assessing adequate health services (Gunzelmann, Schmidt, Albani, \& Brähler, 2006; Kruse \& Wahl, 2010; Mak, 2011). It is a key outcome measure and is considered a predictor and mediator of successful aging (Ferring \& Boll, 2011; Gerstorf, Lövdén, Röcke, Smith, \& Lindenberger, 2007).

Well-being and quality of life are widely discussed and studied concepts in social and economic sciences (Langlois \& Anderson, 2002; Maderthaner, 1998). The general consensus is that well-being is one of the personal aspects of quality of life - in contrast to the external factors like environmental influences (Gunzelmann et al., 2006; Kruse \& Wahl, 2010; Lawton, 1983, 1994). Nevertheless, both terms are often used interchangeably and colloquial (Langlois \& Anderson, 2002). In addition, some researchers argue that wellbeing is a component of quality of life while others define well-being as an outcome of quality of life (Langlois \& Anderson, 2002; Sarvimäki \& Stenbock-Hult, 2000). In this study, the authors examine well-being as a personal and subjective domain of quality of life.

Well-being in general measures 'individuals' subjective perceptions that life as a whole is good' (George, 2010, p. 331f), thus there is a strong link to the fulfilment of needs (Maderthaner, 1998).Well-being is described as a multi-dimensional concept; however, there is 'a distinct lack of conceptual clarity' (Cook, 2008, p. 4; George, 2010; Langlois \& Anderson, 2002). In a broad sense, reviews on well-being discriminate between internal (e.g. psychosocial resources) and external determinants (e.g. social support) (George, 2010).

Bradburn and Noll suggest in 1969 that psychological well-being can be described by positive and negative affect.

Lawton (1994) defines positive affect, negative affect, congruence between desired and attained goals and happiness as its domains. Following research discriminates between positive affect, negative affect, and happiness as affective dimension and domain satisfaction and general life satisfaction as cognitive dimensions of subjective well-being (Diener, 2000; Ferring \& Boll, 2011).

Ryff (1989) focuses on what it means to be mentally healthy and describes the determinants of positive psychological functioning. She proposes a six-factor model, including the dimensions autonomy, environmental mastery, personal growth, purpose in life, positive relations with others and self-acceptance. The Ryff scales of psychological well-being are well accepted under professionals and construct validity is given (Clarke, Marshall, Ryff, \& Wheaton, 2001; Ryff \& Singer, 2006).

Important predictors of well-being in old age are perceived health, functional capacity, good social relationships, an active life and spiritual beliefs (Ferring \& Boll, 2011; George, 2010; Maderthaner, 1998; Sarvimäki \& Stenbock-Hult, 2000). Current research stresses the enormous influence of emotional aspects, e.g. positive and negative affect (Gunzelmann et al., 2006).

Currently, it is ambiguous, to what extend these concepts and findings are reliable for individuals with dementia. Existing models are 'beset with contradictions and inconsistencies' (Cook, 2008, p. 4). Brod, Stewart and Sands (1999) published a concept of general quality of life in dementia partly based on the quality-of-life model of Lawton. It includes the domains sense of aesthetics, positive affect, negative affect, self-esteem and feelings of belonging. This model is not based on self-report nor it focuses on well-being alone. Due to this, it can only act as a guideline here.

Stechl (2006) identifies in her self-report research the need for autonomy, continuity of lifestyle, security and social acceptance/respect, stressing that they vary between individuals and are closely interrelated. These results reflect the early stages of dementia, being potential 
indicators for the present study. However, there is currently no information on the constancy of needs.

Moyle et al. (2011) conduct in-depth interviews with individuals with dementia in longterm care settings. They propose the factors, family, people and things, and highlight the importance of control. Their results focus on general quality of life in dementia but can provide important reference points.

Niebuhr (2004) deduces from her interview study with individuals with dementia living at home the need for social engagement and belonging, affirmation of self, autonomy and independence and provision. However, as no information is provided on cognitive function, the relevance of these results for this study is ambiguous.

The interview study of Schulz-Hausgenoss (2005) considers the patient view of individuals with dementia in impatient facilities, finding the derived key needs to include privacy and housing situation, social contacts, autonomy and options, care and assistance and consideration of previous habits. Although the study provides important reference points for the current question, it relates to the objective aspects, which are not the focus of this study.

Tom Kitwood and the Bradford Dementia Group (Baldwin \& Capstick, 2007; Kitwood, 1997, 2005) developed a conceptualisation of personhood and well-being in dementia. They founded a social-psychological theory of dementia care in contrast to medical or behavioural approaches (Brooker, 2004). Kitwood proposes that an individual with dementia can achieve 'a state of at least relative well-being' (Kitwood \& Bredin, 1992, p. 270), if his personhood is maintained. The term 'personhood' has its origin in client-centred psychotherapy (Rogers, 1961), but in his work on person-centred care Kitwood refers as well to psychoanalytic models (Brooker, 2004). Person-centred care is part of the phenomenological school of psychology, where the 'subjective experience of the individual is seen as reality' (Brooker, 2004, p. 217).

Kitwood defines five psychological needs based on clinical observations to establish the main foci for intervention (Brooker, 2004). First is a need for comfort: to feel 'thoroughly strong', thus 'enabling a person to remain in one piece when they are in danger of falling apart' (Kitwood, 1997, p. 19). The need for attachment 'creates a kind of safety net (...) when the world is full of uncertainty' (Kitwood, 1997, p. 19), supporting the ability to function. Kitwood $(1997,2005)$ speaks of inclusion when individuals with dementia feel accepted within their social surroundings, can participate in life and feel needed; thus, restricting the definition to social and instrumental participation. The need for occupation is defined from the feelings of deep satisfaction and self-esteem (Kitwood, 2005). 'To be occupied means to be involved in the process of life in a way that is personally significant, whether this consists of action, reflection or relaxation' (Kitwood, 1997, p. 20). The need for identity 'involves maintaining a sense of continuity with the past, and some kind of consistency in the present life' (Kitwood, 1997, p. 20). Kitwood (1997) summarises those five great needs 'in the central need for love', but suggests to use only the five for further analysis (p.19). This basic model was frequently adapted and refined (e.g. Dementia Care Mapping), without ever being empirically tested.

Nowell, Thornton and Simpson (2013) explored the subjective experience of personhood in dementia care settings and identified the following themes: First, working out the system and adapting in order to survive it, second, using past and future roles and experiences to manage the present and third, being both an individual and a member of the group. Their interview study does not refer explicit to Kitwood's model of needs but provides important reference points. 
Methodological problems arise when researchers try to examine well-being from the subjective perspective of the individuals with dementia. Their self-assessment ability is considered a controversial construct (Vogel et al., 2004). Obtaining reliable self-reports from individuals with dementia is challenging due to impaired memory, attention, insight and communication skills (Ettema et al., 2007; Trigg et al., 2011). However, the subjective nature of well-being means that the value of proxy and observational assessments is limited (Ferring \& Boll, 2011; Mak, 2011; Roick, Hintz, \& Gertz, 2007; Trigg et al., 2011).

Currently, there is no consensus on the reliability of self-report in dementia (Ferring \& Boll, 2011; Mak, 2011). Apparently, specific skills like language capacity, concentration or self-reflection are more important than the severity of dementia, e.g. the Mini Mental State Examination (MMSE) score (Gräske, Fischer, Kuhlmey, \& Wolf-Ostermann, 2012; Mozley et al., 1999; Roick et al., 2007). Evidence is growing, however, that many individuals with dementia can contribute meaningfully to questions about their well-being (Gräske et al., 2012; Mak, 2011; Roick et al., 2007; Trigg et al., 2011). The interviewer has to be communicatively competent and trained empathically and the survey method should be adapted to the abilities of the individuals with dementia (Dewing, 2002; Ferring \& Boll, 2011). For example, even individuals scoring $>3$ on the MMSE can manage the QoL-ADQuestionnaire (Hoe, Katona, Roch, \& Livingston, 2005).

Therefore, self-report studies generally concentrate on people with mild dementia and there is a great need for research on the subjective experience of individuals suffering from moderate and severe dementia (Ferring \& Boll, 2011; O'Connor et al., 2007). Kitwood and his work on person-centred care focus on the subjective experience of personhood in dementia and he developed a conceptualisation of well-being in dementia. Thus, his theoretical work meets the research purpose best.

The study aimed to examine the empirical relevance of Tom Kitwood's model of psychological needs against the background of the subjective experiences of individuals with moderate or severe dementia, further to elaborate this model in order to develop a conceptual framework of well-being of individuals with moderate or severe dementia.

The authors defined well-being as an indicator of the quality of life. It is a multidimensional construct which describes to what extent the psychological needs of an individual with dementia are subjectively met.

\section{Methods}

\section{Qualitative content analysis}

A deductive-inductive research design was used. First, the authors took the five given coding categories (called domains) from Kitwood's model of needs - comfort, attachment, inclusion, occupation and identity, - and searched the data for text that matches the categories.

In the inductive analysis step, the assigned text units were paraphrased. Subcategories (called 'components') were generated inductively from the data by summarising content analysis (Mayring, 2007). Each component was defined as a concrete dimension of a need. It represents the similar experiences and views of individuals with dementia referring to one need. Thus, the categorisation system is a hierarchical summary of the components. In addition, a new main category (called domain) was derived directly and inductively from the raw data. As new categories emerged, Kitwood's model was modified and elaborated. 


\section{Participants (Table I)}

A German special long-term care unit for individuals with moderate or severe dementia was selected to design the sample. All the 30 residents of this Special Care Unit (SCU) were asked to participate.

Informed consent was sought from the individuals with dementia in a three-stage process as proposed by Allan (2001). First, legal approval was obtained from the legal representative (e.g. lawyer or the nearest relative). Second, at each face-to-face encounter, the interviewer explained the study to the individual with dementia and asked for consent. Third, during the interview, the interviewer was looking for verbal, non-verbal or behavioural indicators of consent or disconsent (Dewing, 2002).

Twenty-three individuals agreed to participate. One resident with primary depression and three with global aphasia certified by staff were excluded. Nineteen residents were recruited, with average age 82 years, range $72-91$ years; 13 participants $(68 \%)$ were female. Average duration of stay was 33 months, and average cognitive function was nine points $(n=17)$, range $0-25$. The study met the ethical standards of the University Human Research Ethics Committee and the residential care management.

This study cannot claim to be representative but presents the basic concepts.

\section{Measures}

Well-being. An individual interview method was chosen to encourage the participants to talk in personal terms. A semi-structured interview was developed based on the theoretical framework of Kitwood's model and a focus group discussion. In the focus group, a neurologist, a nurse, a social worker, a psychologist and a nursing home administrator took part, each of them with considerable expertise in working with individuals

Table I. Characteristics of participants $(N=19)$.

\begin{tabular}{lll}
\hline Variables & & \\
\hline Age (years) & Mean (SD) & $82.42(5.07)$ \\
& Range & $72-9$ I \\
Duration of stay (months) & Mean (SD) & $33($ I5.26) \\
& Range & $3-48$ \\
Gender female & $\%$ & 68.42 \\
Cognitive function (MMSE) & Mean (SD) \\
Scores 20-25 & $N$ & $9.4 I(6.01)$ \\
Scores I0-19 & $N$ & 2 \\
Scores 0-9 & $N$ (of which invalid) & 5 \\
\hline
\end{tabular}

aild dementia.

${ }^{b}$ Moderate dementia.

'Severe dementia. 
Table 2. Key questions in focus group discussion and semi-structured interviews.

\begin{tabular}{|c|c|c|}
\hline & Focus group & Semi-structured interview \\
\hline Comfort & $\begin{array}{l}\text { What comforts individuals with dementia } \\
(\operatorname{IwD}) \text { ? }\end{array}$ & $\begin{array}{l}\text { When you are having a bad day, what is } \\
\text { lifting you up again? }\end{array}$ \\
\hline Inclusion & What gives IWD a feeling of belonging? & $\begin{array}{l}\text { Do you feel lonely sometimes? } \\
\text { What helps you when feeling lonely? }\end{array}$ \\
\hline Identity & $\begin{array}{l}\text { What gives an IWD the insurance of still } \\
\text { being an autonomous person? }\end{array}$ & $\begin{array}{l}\text { After moving into your new home, what } \\
\text { helped you to settle in? }\end{array}$ \\
\hline Occupation & $\begin{array}{c}\text { What gives IWD the feeling of being } \\
\text { needed and valuable (or useful)? }\end{array}$ & What gives you some variety? \\
\hline Attachment & $\begin{array}{l}\text { What gives IWD the feeling of having } \\
\text { reliable relationships (or partners)? }\end{array}$ & $\begin{array}{l}\text { When you are feeling bad, on whom you } \\
\text { can rely on? }\end{array}$ \\
\hline
\end{tabular}

with dementia. In an audio-taped discussion, they reflected questions referring to Kitwood's psychological needs (Table 2).

The penultimate version of the interview guide contained the five general key questions of the pilot version (Table 2). It was completed by some supportive questions which derived out of the focus group discussion. After two introductory interviews, the authors revised the interview guide. Interviews were conducted by one interviewer during a period of two weeks and adapted to the needs of the respondents, as proposed by Dewing (2002) or Murphy, Gray, van Achterberg, Wyke and Cox (2010). For example, verbal and non-verbal communication was used, and at first, open-ended questions were asked. The questions were simple, short and one-dimensional in order to meet the respondent's mental and linguistic capabilities. The researcher tried focusing on the implied meaning, rather than looking for the correct language use. The interviewees were given as much time as they needed for responding and they had the opportunity to talk in indirect ways. The interviews could take place everywhere, could be conducted even while walking, and interrupted on demand. They usually took 30-60 min, were audio-taped and transcribed verbatim. In the transcripts, the interviewer made notes of the non-verbal signals after each interview.

Dementia severity. The MMSE as a measure of cognitive function, with a maximum score of 30 points, was used (Folstein, Folstein, \& Mc Hugh, 1975). Although the cognitive impairments in dementia 'can vary from day to day' (Murphy et al., 2010, p.458), it is a common practice within the biomedical paradigm to categorise people in stages of dementia. Depending on the research objective and the participants, different grades can be used to classify the stages (Ivemeyer \& Zerfaß, 2002). In the current study, severe dementia was classified with 0-9 points, including a severe memory loss with only fragments remaining. The individual is assumed to be only oriented to his person, disoriented to time and place and unable to make judgements or solve problems. Moderate dementia was classified with 10-19 points and included a severe memory loss with only highly learned material to be retained. Mild dementia was classified with $20-25$ points and included a moderate memory loss, which interfered with everyday activities. Measurements were completed at the end of the interview. 
Age, sex, diagnoses and duration of stay. The data were obtained from the institutional records.

\section{Analysis}

The interview material was completely transcribed verbatim as a literary transcript, additionally including non-verbal signals to validate meaning. According to the theoretical framework of Kitwood's model of needs, the authors first generated deductively an initial list of the five coding categories - comfort, attachment, inclusion, occupation and identity. They created a coding manual by defining the categories, giving a typical categorisation example and fixing the rules for assigning codes. The coding rules were applied to the entire corpus of interviews, coding all the text.

Next, content analysis (Mayring, 2007) was conducted with MAXQDA 10 (2010). The material was paraphrased to summarise the contents. Wherever possible, the words of the interviewee were used (Mayring, 2007). These paraphrases were generalised as an impersonal statement at the required level of abstraction. Next, the material was reduced by deleting coding units with the same meaning (selection) and combining those with similar meaning (grouping).

This inductive approach allowed new themes to emerge from the data: The five main categories were broken into subcategories (components), and a new category (domain) was identified.

Each component was tested for selectivity, defined and provided with a typical categorisation example. The authors confirmed that each domain and component had been cited by individuals with dementia.

For inter-rater reliability a second researcher independently coded one interview according to Kitwood's domains, termed 'consensual coding' (Schmidt, 2000, p. 453). The inter-rater agreement was $87.5 \%$ before consultation and $91.6 \%$ after discussion of discrepancies. Thus, the inter-rater reliability Kappa value was $>.87$ between individual raters. The proportion of usable material in this edited interview was 98 .

\section{Results}

Content analysis generated 30 descriptive components. They broke down the five domains of Kitwood in subcategories and added a new one (Figure 1). Each of the six domains and its components are described below.

\section{Comfort}

Individuals with dementia experience comfort when they feel 'thoroughly strong' (Kitwood, 1997, p. 19). The analysis discovered eight components.

'Pleasure': The participants find comfort in the small pleasures of life providing them relaxation and well-being. Particular pleasure stimuli vary between participants; e.g. for Edwin this is music. 'Interaction': Individuals with dementia console themselves by seeking real human contact, including with family, cohabitant or children. For example, Igor says, 'When someone visits me and when they stay here, then I'm happy'. In contrast to this consoling interaction, contact in combination with a high degree of emotion was coded under 'attachment'. 


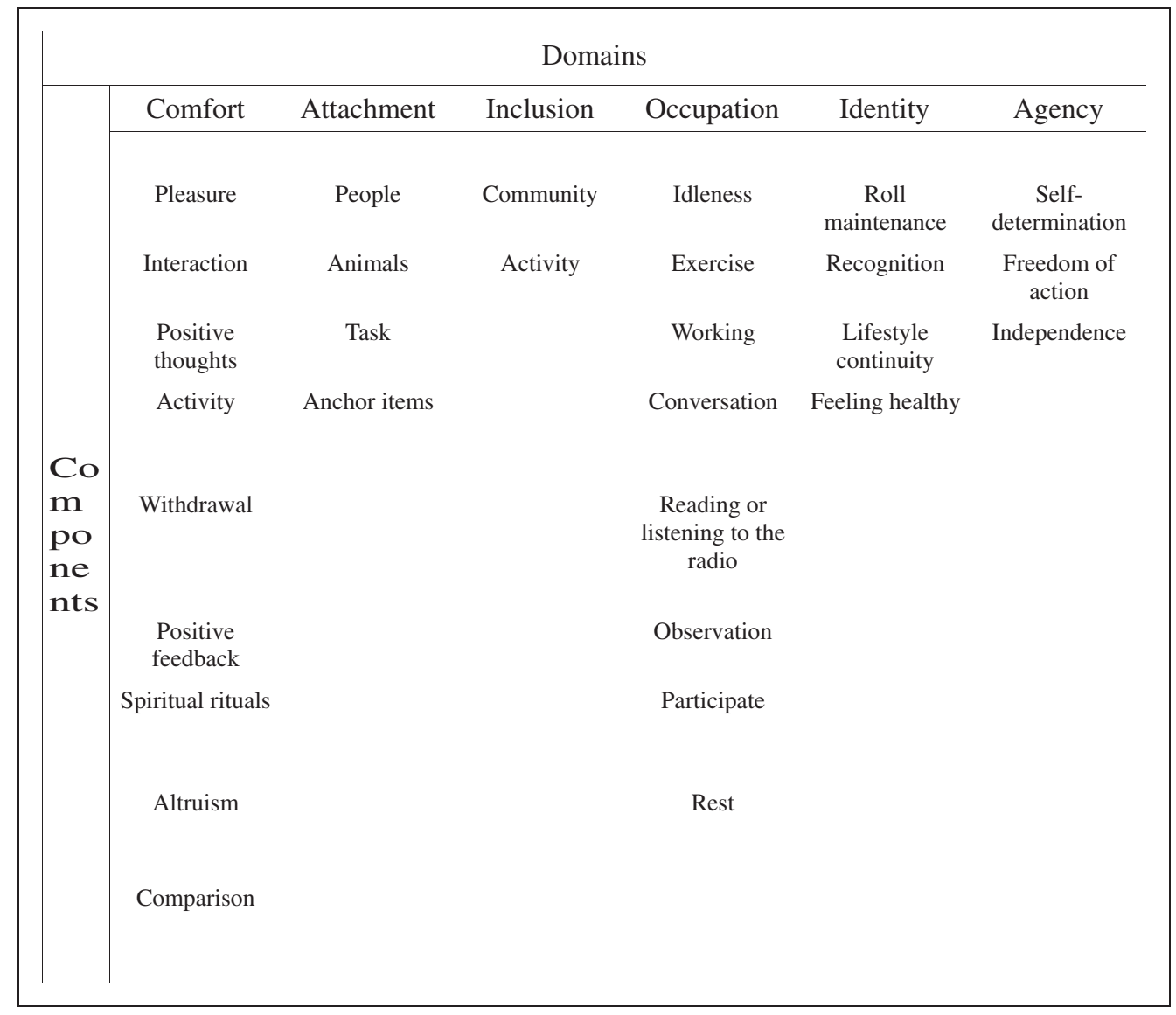

Figure I. Conceptual framework of subjective well-being in dementia.

In 'positive thoughts', individuals with dementia console themselves by remembering good old times and hoping for better times.

There is always the hope that it will get better (...) One cannot live without hope. (...) I play with my thoughts, I think of how it was before. And then I just hope that it will be like that again. (Ben)

Some participants like Clarisse find comfort in 'activity'. She explains: '[When I feel bad,] then I go out. Then I go for a walk. Then I visit somebody. Then it is fine again'. Other residents prefer 'withdrawal', representing a response to sadness. For example, Kelly points out, 'The peace, the peace [it is good for me] and (...) to be alone again'. 'Positive feedback from others', including being praised, approved or reassured, appears to be an important form of comfort for participants with very low cognitive resources (very low or nonmeasurable MMSE). Fanny, with a MMSE score of 0 points, explains: 'And then they said to me: They are happy about you [me]. - And then that is nice'. Some residents find 
comfort in 'spiritual rituals', 'altruism' or temporal or social 'comparing'. For example, Queenie says, 'Indeed, it comforts me, if I can help somebody'. Ben states: '[Feeling] bad? In the last decades I never felt bad really. I had bad times in war captivity, but this is years ago. It is already 50 years ago'.

The need for comfort is frequently confirmed in the data material, with many individuals with dementia having strategies for self-comfort.

\section{Attachment}

Four components constitute the need for attachment, with attachment to 'individuals' mentioned most, being particularly intimate with living or deceased people. Individuals like Sarah talk about them, seek their company and rely on their support: 'When my grandchildren cling to me, (...) that makes me happy. Yes'. While Kitwood indicates this need being exclusively associated with people, there are significantly more components in the data material. 'Animals' are also an important resource for attachment. Sarah is shouting encouraged: ,A pet! A cat, a small cat! Cat, yes. Yes, a cat. Yes, yes, yes, this ..., this is so good!'

An attachment to an appropriately demanding 'task' can satisfy this need as well. For Dora this task is cleaning. She is sitting in the living room, spitting on the table and cleaning it with a cotton handkerchief again and again. She explains:

This is a nice work! This is an easy work! (...) This is no hard work (...) [is putting the handkerchief away] Alas. [I: Now the work is done, isn't it?] That's what I love! [laughs]

That's what I love! [I: What is bothering you?] If it doesn't come to an end. (Dora)

Another important component not yet described in the literature is 'anchor items'. Some individuals with dementia satisfy their need for attachment with objects about which they are sentimental. The following quotation from Igor is a typical example: 'Yes, the dog [a soft toy] (...) there (...), it is so cute [laughs]. (...) Makes it happy when someone has it [laughs]. Yes, I have a much better Festgesallt with it, than . . . - ah!' The word 'Festgesallt' seems to be a neologism for 'relationship', because it sounds similar to the German word 'Verhältnis'.

\section{Inclusion}

Inclusion primarily means being part of a 'community'. This can be with cohabitants, a circle of friends or the family. This need is fulfilled when an individual with dementia has a feeling of recognition, feels accepted and equal, and is met with understanding. Interviewee Henry expresses: 'Sorrow, sorrow brings me nothing. I am therefore in some way still part of the family'. When asked if she sometimes feels alone, his cohabitant Clarisse points out:

No, really no. I always have some entertainment. There are so many. (...) I already know some people with whom I like to be together. (...) And with them we meet each other. This is really nice. (...) I mean, I chose the people with whom I like to be together. (...) And then it is nice, isn't it?' (Clarisse)

Additionally, participants frequently want to be included in 'activities' in their environment. Thus, Queenie believes a good day is when 'others... also let one watch them at their work'.

Thus, Kitwood's definition is consistently confirmed by the results. 


\section{Occupation}

The need for occupation is subdivided into eight components. Most frequently mentioned is 'idleness', thus leisure and doing nothing constitute a form of occupation. For example, Henry expresses, because of his age he only feels like 'lazing about'. 'Exercise' and 'working' are further possibilities for self-occupation. Edwin phrases this as, '[I] choose some points here and let them go around in my head. (...) But, I always find a job. (...) It's not as if I'm unoccupied if at times I don't get anything to do'. The component 'conversation' normally involves the exchange of trivialities. When asked what she is doing the whole day long, Kelly states:

There is as a lot babbling [local dialect for speaking]. (...) Back and forth, this and those. (...) Then we go for a walk already, a little bit up and down. Then one goes to another, open the door, close the door (...) [and says:] Until tomorrow morning again, ok? (Kelly)

'Reading and listening to the radio' also fulfil the need for occupation. '[Here it is] hardly, hardly boring. (...) There is time and again something to tide oneself over, (...) e.g. by putting on good music', Sarah says. The component 'observation' is particularly pronounced by interviewee Tamara, whereby occupation means watching events around her and commenting on them.

That I look at now. [checks on an employee, who goes by] (...). You must see this! (...) Just look at that now! [The laundry is being distributed] (...) Yes, I sometimes say (...): Can't you do so?

(...) She also says: Oh, can't you do that differently, differently? (Tamara)

Further components of occupation are to 'participate', meaning taking part in the offers at the special care unit, and to 'rest'. Clarisse gives an example for the components 'exercise' and 'rest': 'Most of the time when I feel bored, then I lay down. And mostly I can fall asleep. And when I can't fall asleep, then I'm not more satisfied, then I get up again. And go for a walk'.

\section{Identity}

Data analysis revealed four components. 'Role maintenance' means to feel approved in the roles carried out in daily life. This generally involves occupational and family roles, and the related attributes. When asked what has pleased them recently, Veronica says: 'Enjoyed? That my children were born [laughs]' and Fanny answers: ' ... and then soon they told me my name. This was nice'. 'Recognition' for the interviewed individuals with dementia is the acceptance of their feelings and their humanity. For this purpose, the participants repeat their previously effective coping strategies, characteristics or life experiences. 'I have the matter in hand. And I will stick to that', Queenie says. 'Lifestyle continuity', the subjective assessment that living conditions, life rhythms and habits have hardly changed, also fulfils the need for identity, manifesting itself in sovereignty and satisfaction. Kelly indicates this by saying: 'Been here so long already. (. . .) I do my stuff [things] because when I come here I eat - I am satisfied'. 'Feeling healthy' is a need component only formulated by participants with a MMSE score above 15. Amanda, the participant with the highest MMSE score, says: '[if I could] turn back time, to when things were better for me (...), then I would be happy (...)'. The quotations indicate that this need is satisfied when the interviewee subjectively experiences mental and physical health in personally important areas. 


\section{Agency}

This domain was added, because some paraphrases could not be assigned to any other domain. They could be summarised in three components. First, there is 'selfdetermination', including the wish to be informed in an understandable manner and to be asked. In Clarisse's opinion, she had chosen her cohabitants herself, which pleased her. Second, some interviewees show a strong need for 'freedom of action', wishing to move freely, determine themselves their place of residency, do the things they like and receive the absolute minimum help. For example, Edwin says: 'If I can't move myself just how I would like to, then that would not be good'. Igor explains: 'If someone lives here, he really knows that he won't get out of here again. (...) Yes, and when he needs it, then he is crying about this'. Third, some individuals with dementia formulate the need for 'independence', which means being self-sufficient and no longer dependent on help. Amanda points out: 'Well, I always preferred to do everything by myself, (...) and that just doesn't happen anymore and [that is very difficult for me]'. The authors suggest calling this need agency. The three mentioned components give the interviewees a feeling of selfefficacy and self-worth.

The composition of the category system is summarised in Figure 1.

\section{Discussion}

The resulting model with 30 components over six domains is extraordinarily diverse. All the domains postulated by Kitwood were empirically supported. Nevertheless, the analysis revealed a number of differences between Kitwood's definition and the individuals with dementia's experience. The comments on comfort illustrate that many individuals with dementia can help themselves. This active contribution to maintenance of well-being is recognised in other studies (e.g. Cook, 2008; Nowell et al., 2013). Kitwood's definition of attachment is extended from referring to people to also including animals, tasks and items. In the field inclusion, many results are replicated from Niebuhr (2004), Schulz-Hausgenoss (2005) and Stechl (2006), which also identify components such as 'social acceptance' and 'belonging'. Subjective continuity with the past, as an aspect of identity, - as postulated by Kitwood - makes a crucial contribution to well-being, an assumption also expressed by Cook (2008) and Nowell et al. (2013). Other parallels are exhibited by the components of identity to the results of Stechl (2006), Niebuhr (2004) and Schulz-Hausgenoss (2005), with 'life style continuity' and 'recognition of oneself' also taken from their material. The component 'feeling healthy' was only mentioned by five participants $(26 \%)$, despite the importance of health in generic models of well-being. This may reflect that subjective health-related well-being increases in moderate and severe dementia.

Additionally, some interviewees express the need for 'self-determination', 'freedom of action' or 'independence'. Those components exhibit similarities to results of SchulzHausgenoss (2005) and Niebuhr (2004). They describe needs for 'choices' and 'autonomy'. Cook (2008) similarly emphasises that feelings of 'control', 'freedom of choice' and 'independence' contribute to well-being. Moyle et al. (2011) mention a lack of opportunity for 'decision-making' and 'feeling free'. Nowell et al. (2013) highlight the negative impact of a 'global and pervasive' lack of choice (p. 399).

Therefore, Kitwood's conceptual framework needs to be extended. The suggested domain is called agency, because Kitwood himself describes agency as one of four global sentient 
states of well-being. He means 'the ability to control personal life in a meaningful way, to produce, to achieve, to make some mark upon others and the world' (Kitwood \& Bredin, 1992, p.283).

Some interviewees make unreal, but subjectively accurate assessments, for example if they speak about deceased parents like they were living. This raises the question of selfassessment ability in dementia. Some parts of their opinion are not in accordance with other shared social reality. On the other hand, cognitively healthy people do not always have a logically understandable opinion either. Their opinion is influenced by individual attributes and experiences. Therefore, it is imperative that any assessment of well-being is based on current, subjective perceptions, as indicated here by the minor importance of health. Proxy reports are only of limited validity, because everybody else is an outsider in the subjective experience of individuals with dementia.

The results also question the use of observational methods for measuring subjective wellbeing. For example, the theme 'rest' has four different functions for the interviewees: resting, idleness, withdrawal and observing. While these meanings could be raised by self-report, they were probably not detected by a monitoring procedure.

The speech comprehension of some of the interviewees must be highlighted, whereby the interviewer during the interview could not always recognise in a given answer the reference to the question. But consensual, qualitative analysis showed in retrospect that only $2 \%$ of the coding units were unusable. The high proportion of usable material substantiates the competence of the interviewees.

Regarding the limits of self-assessment ability in dementia, fluctuating attention, restlessness, strongly reduced retention and severe slowdown challenged the interviewer but did not necessarily lead to the exclusion of the respective participant. Through the described changes to the interview methodology, these challenges could often be met. However, the loss of speech automatically led to exclusion.

This study obtained self-reports from participants with moderate and severe dementia. The high inter-subjective comprehensibility of the interpretation emphasises its objectivity. Parallels with the results of Niebuhr (2004), Stechl (2006), Schulz-Hausgenoss (2005), Cook (2008), Moyle et al. (2011) and Nowell et al. (2013) are evidence of validity. This study provides valuable contributions to the understanding of needs of individuals with moderate and severe dementia.

\section{Limitations of the study}

Because the participants were all living in the same special care unit, the findings cannot be generalised. They are of heuristic value.

Further work is required to develop and validate a standardised questionnaire of the psychological needs and to determine whether the need for agency is an independent domain. Further qualitative work (e.g. a contrast of cases) could address inter-individual (e.g. cohort related) differences in psychological needs.

\section{Conclusions}

Despite the limitations, this study strengthens the case that individuals with dementia are potentially important informants of their subjective well-being. Furthermore, the developed conceptual framework of subjective well-being in dementia represents the experiences of 
individuals with dementia. The study provides indications that Kitwood's model has empirical relevance. The authors suggest an extension to the domain agency. The study provides valuable contributions to evidence-based, theoretical conceptualisation of wellbeing in dementia and to the limits and potential of self-report in dementia.

\section{Declaration of Conflicting Interests}

The author(s) declared no potential conflicts of interest with respect to the research, authorship, and/or publication of this article.

\section{Funding}

The author(s) received no financial support for the research, authorship, and/or publication of this article.

\section{References}

Allan, K. (2001). Communication and consultation: Exploring ways for staff to involve people with dementia in developing services. Bristol, UK: The Policy Press.

Baldwin, C., \& Capstick, A. (Eds.) (2007). Tom Kitwood on dementia. A reader and critical commentary. Maidenhead, NY: Open University Press.

Bradburn, N. M., \& Noll, C. E. (1969). The structure of psychological well-being. Chicago, IL: Aldine Pub. Co.

Brod, M., Stewart, A. L., \& Sands, L. (1999). Conceptualization of quality of life in dementia. Journal of Mental Health \& Aging, 5, 7-19.

Brooker, D. (2004). What is person-centred care in dementia? Reviews in Clinical Gerontology, 13, 215-222.

Clarke, P. J., Marshall, V. W., Ryff, C. D., \& Wheaton, B. (2001). Measuring psychological well-being in the Canadian Study of Health and Aging. International Psychogeriatrics, 13, 79-90.

Cook, A. (2008). Dementia and well-being. Possibilities and challenges. Edinburgh, UK: Dunedin Academic Press Ltd.

Dewing, J. (2002). From ritual to relationship. A person-centred approach to consent in qualitative research with older people who have a dementia. Dementia, 1, 157-171.

Diener, E. (2000). Subjective well-being. The science of happiness and a proposal for a national index. American Psychologist, 55, 34-43.

Ettema, T. P., Hensen, E., de Lange, J., Dröes, R. M., Mellenbergh, G. J., \& Ribbe, M. W. (2007). Self report on quality of life in dementia with modified COOP/WONCA charts. Aging \& Mental Health, 11, 734-742.

Ferring, D., \& Boll, T. (2011). Subjective well-being in older adults: Current state and gasp of research. In L. Bovenberg, \& A. Van Soest (Eds.), Aging, health and pensions in Europe. An economic and social policy perspective (pp. 173-205). London, UK: Palgrave Macmillan.

Folstein, M. F., Folstein, S. E., \& McHugh, P. R. (1975). 'Mini Mental State': A practical method for grading the cognitive state of patients for the clinician. Journal of Psychiatric Research, 12, 189-198.

George, L. K. (2010). Still happy after all these years: Research frontiers on subjective well-being in later life. Journal of Gerontology: Social Sciences, 65B, 331-339.

Gerstorf, D., Lövdén, M., Röcke, C., Smith, J., \& Lindenberger, U. (2007). Well-being affects changes in perceptual speed in advanced old age: Longitudinal evidence for a dynamic link. Developmental Psychology, 43, 705-718. 
Gräske, J., Fischer, T., Kuhlmey, A., \& Wolf-Ostermann, K. (2012). Quality of life in dementia careDifferences in quality of life measurements performed by residents with dementia and by nursing staff. Aging \& Mental Health, 16, 819-827.

Gunzelmann, T., Schmidt, S., Albani, C., \& Brähler, E. (2006). Lebensqualität und Wohlbefinden im Alter. Zeitschrift für Gerontopsychologie \& -psychiatrie, 19, 7-15.

Hoe, J., Katona, C., Roch, B., \& Livingston, G. (2005). Use of the QOL-AD for measuring quality of life in people with severe dementia - The LASER-AD study. Age and Aging, 34, 130-135.

Ivemeyer, D., \& Zerfaß, R. (2002). Demenztests in der Praxis. Ein Wegweiser. München, Germany: Urban \& Fischer Verlag.

Kitwood, T. (1997). The experience of dementia. Aging \& Mental Health, 1, 13-22.

Kitwood, T. (2005). Demenz. Der person-zentrierte Ansatz im Umgang mit verwirrten Menschen (4, unveränderte Auflage). Bern, Göttingen, Toronto, Seattle: Hans Huber Verlag.

Kitwood, T., \& Bredin, K. (1992). Towards a theory of dementia care: Personhood and well-being. Aging and Society, 12, 269-287.

Kruse, A., \& Wahl, H. W. (2010). Zukunft Altern. Individuelle und gesellschaftliche Weichenstellungen. Heidelberg, Germany: Spektrum Akademischer Verlag.

Langlois, A., \& Anderson, D. E. (2002). Resolving the quality of life/well-being puzzle: Towards a new model. Canadian Journal of Regional Science, 25, 501-512.

Lawton, M. P. (1983). Environment and other determinants of well-being in older people. The Gerontologist, 3, 349-357.

Lawton, M. P. (1994). Quality of life in Alzheimer disease. Alzheimer Disease and Associated Disorders, $8,138-150$.

Maderthaner, R. (1998). Wohlbefinden, Lebensqualität und Umwelt. In I. Kryspin-Exner, B. LuegnerSchuster, \& G. Weber (Eds.), Klinische Psychologie und Gesundheitspsychologie - Postgraduelle Ausund Weiterbildung (pp. 483-508). Wien, Austria: WUV, Universitätsverlag.

Mak, W. (2011). Self-reported goal pursuit and purpose in life among people with dementia. Journal of Gerontology: Psychological Sciences, 66b, 177-184.

Mayring, P. (2007). Qualitative Inhaltsanalyse. Grundlagen und Techniken (9. Auflage). Weinheim, Germany: Deutscher Studien Verlag.

MAXQDA 10 (2010). The art of text analysis. Retrieved from http://www.maxqda.de/

Moyle, W., Venturto, L., Griffiths, S., Grimbeek, P., McAllister, M., Oxlade, D.,...Murfield, J. (2011). Factors influencing quality of life for people with dementia: A qualitative perspective. Aging \& Mental Health, 15, 970-977.

Mozley, C. G., Huxley, P., Sutcliffe, C., Bagley, H., Burns, A., Challis, D., ... Cordingley, L. (1999). 'Not knowing where I am doesn't mean I don't know what I like.' Cognitive impairment and quality of life responses in elderly people. International Journal of Geriatric Psychiatry, 14, 776-783.

Murphy, J., Gray, C. M., van Achterberg, T., Wyke, S., \& Cox, S. (2010). The effectiveness of the Talking Mats framework in helping people with dementia to express their views on well-being. Dementia, 9, 454-472.

Niebuhr, M. (2004). Interviews mit Demenzkranken: Wünsche, Bedürfnisse und Erwartungen aus Sicht der Betroffenen. Köln, Germany: Kuratorium Deutsche Altershilfe.

Nowell, Z. C., Thornton, A., \& Simpson, J. (2013). The subjective experience of personhood in dementia care settings. Dementia, 12, 394-409.

O'Connor, D., Phinney, A., Smith, A., Small, J., Purves, B., Perry, J.,... Beattie, L. (2007). Personhood in dementia care. Developing a research agenda for broadening the vision. Dementia, 6, 121-142.

Rogers, C. R. (1961). On becoming a person. Boston, MA: Houghton Mifflin.

Roick, C., Hintz, A., \& Gertz, H. -J. (2007). Is quality of life in dementia patients validly estimable? A current review about measuring instruments and methodological problems. Psychiatrie und Praxis, $34,108-116$. 
Ryff, C. D. (1989). Happiness is everything, or is it? Explorations on the meaning of psychological wellbeing. Journal of Personality and Social Psychology, 57, 1069-1081.

Ryff, C. D., \& Singer, B. H. (2006). Best news yet on the six-factor model of well-being. Social Science Research, 35, 1103-1119.

Sarvimäki, A., \& Stenbock-Hult, B. (2000). Quality of life in old age described as a sense of well-being, meaning and value. Journal of Advanced Nursing, 32, 1025-1033.

Schmidt, Ch. (2000). Analyse von Leitfadeninterviews. In U. Flick, E. von Kardorff, \& I. Steinke (Eds.), Qualitative forschung (pp. 447-454). Hamburg, Germany: Reinbek Verlag.

Schulz-Hausgenoss, A. (2005). Lebensqualität bei Demenz. Vorlesungsreihe U3L 'Soziale Gerontologie' Johann-Wolfgang-Goethe Universität Frankfurt. Retrieved from http://www.u31.uni-frankfurt.de/ downloads/Schulz-Hausgenoss3.pdf.

Stechl, E. (2006). Subjektive Wahrnehmung und Bewältigung der Demenz im Frühstadium. Eine qualitative Interviewstudie mit Betroffenen und ihren Angehörigen. Berlin, Germany: Dr. Köster Verlag.

Trigg, R., Watts, S., Jones, R., \& Todd, A. (2011). Predictors of quality of life ratings from persons with dementia: The role of insight. International Journal of Geriatric Psychiatry, 26, 83-91.

Vogel, A., Stokholm, J., Gade, A., Andersen, B. B., Hejl, A. -M., \& Waldemar, G. (2004). Awareness of deficits in mild cognitive impairment and Alzheimer's disease: Do MCI patients have impaired insight? Dementia and Geriatric Cognitive Disorders, 17, 181-187.

\section{Author Biographies}

Elke G Kaufmann is Gerontologist and Social Worker at the Lutheran Diakoniewerk Neuendettelsau. She has an interest in research with older people, exploring the subjective experience of dementia.

Sabine A Engel is a Professor of Social Gerontology at the Catholic University of Applied Sciences of North Rhine-Westphalia and member of the Friedrich-Alexander University of Erlangen-Nuremberg, Institute of Psychogerontology. She has been lecturing in social gerontology at university for more than 10 years. One of the key areas of her gerontological research is focussed on the situation of informal caregivers of people with dementia and on the subjective experience of people with dementia. She has developed and evaluated 'EduKation', a psycho-educative program for informal caregivers of people with dementia. 